\title{
In vitro seed germination and node culture of the nutraceutical plant Grewia tenax
}

\author{
Hussien M. Daffalla ${ }^{1 *}$, Azza M. Elsheikh ${ }^{1}$, Hiba A. Ali', Mutasim M. Khalfala ${ }^{2}$ \\ ${ }^{1}$ Commission for Biotechnology and Genetic Engineering, National Centre for Research, 11111 Khartoum, Sudan \\ ${ }^{2}$ College of Public Health and Health Informatics, Umm Al-Qura University, P.O. Box: 13174, Postal Code 21955 Al-Acidify, MacKay, \\ Kingdom of Saudi Arabia \\ ${ }^{\star}$ Corresponding author, E-mail: hdaffalla@yahoo.com
}

\begin{abstract}
Grewia tenax is an important nutraceutical plant threatened due to excessive fruit collection and physiological dormancy of seeds. In vitro propagation is required for ex situ conservation of this neglected plant. Improving germination rate is vital for providing the uniform explant material required for propagation and in vitro studies. The aim of this study was to optimize cultivation conditions for in vitro seed germination and micropropagation of G. tenax. Full seed germination was achieved in all treatments. Tests in distilled water medium showed the least number of days for germination and highest seedling length. Full Murashige and Skoog medium produced the maximum number of nodes. Darkness promoted germination rate and seedling length, but decreased the number of nodes per seedling. Benzyladenine and kinetin slightly increased the number of nodes compared to the control. Each uninodal explant cultivated on Murashige and Skoog medium free of plant growth regulators developed into a plantlet within one week. Well-rooted plants were successfully established in a greenhouse with $95 \%$ survival rate. This plant growth regulator-free system can successfully overcome seed dormancy and provide a rapid-continuous supply of plant material of G. tenax.
\end{abstract}

Key words: conservation, Grewia tenax, in vitro propagation, nutraceutical plant, self-rooting seedlings.

Abbreviations: BA, benzyladenine; DMRT, Duncan's Multiple Range Test; DRG, days required for germination; Kin, kinetin; MS, Murashige and Skoog; PGR, plant growth regulator.

\section{Introduction}

Grewia tenax (Forssk.) Fiori (Malvaceae) is a tropical shrub up to $3 \mathrm{~m}$ height (Gebauer et al. 2007; Sharma, Patni 2012). It is a very important wild fruit-producer and prime supplier for food especially during time of food shortages (El Tahir, Gebauer 2004). It is also a source of income for rural populations, by sale of the fruits and other products (Gebauer et al. 2007; Sharma, Patni 2012). Medicinally, various extracts are used to cure ailments e. g. trachoma, tonsillitis, pulmonary, jaundice, rheumatism, asthma infections and are used as a poultice to treat swellings (El Ghazali et al. 1997). G. tenax grows in semi-arid and subhumid climates such as in the semiarid savanna zone in Sudan, where it is an extremely important plant species to the local population (Saied et al. 2010). G. tenax is considered as one of the most affected fruit trees, due to deterioration of the vegetation cover and disappearance of trees (El Tahir, Gebauer 2004; Gebauer et al. 2007).

G. tenax is an endangered species (Anonymous 2000); it has been insufficiently studied and as little is known about ways to improve propagation and early seedling establishment (Gebauer et al. 2007; Saied et al. 2010). Experimental studies indicate that the seeds of G. tenax have physiological dormancy which needs pretreatment for germination (Sharma, Patni 2012). Seed germination is difficult and poor, and slightly older seeds, e.g. one year after collection, germinate better (Saleem et al. 2012). Vegetative propagation of $G$. tenax is possible from cuttings but tends to be low, maximum 61\% (El-Siddig et al. 2005). The exhaustive use of the plant, low viability and poor germination of seeds contributed to the endangered status of the plant in this arid region.

It was generally assumed that seedling explants are, more responsive than explants derived from mature trees (Daffalla et al. 2011). In vitro regeneration techniques for the clonal propagation and in vitro conservation of these rare and endemic species might be useful for maintaining its population. The present investigation was carried out to develop a simple, reliable and efficient protocol for micropropagation of $G$. tenax using seed explants.

\section{Materials and methods}

\section{Plant material and explant preparation}

Fully ripe fruits of Grewia tenax were collected in late August 2012 from plants grown in the Sudan University of Science and Technology campus, Khartoum, Sudan. The fruits were soaked in water for $24 \mathrm{~h}$ to remove pulp manually. The obtained clean and healthy seeds were air- 
dried and kept in refrigerator for further use.

\section{Basal media and culture conditions}

Murashige and Skoog (MS) medium (Murashige, Skoog 1962) was utilized in all experiments. The medium was supplemented with $3 \%$ sucrose and solidified with $0.8 \%$ $\operatorname{agar}(\mathrm{w} / \mathrm{v})$. The $\mathrm{pH}$ of the medium was adjusted to 5.8 before autoclaving at $121^{\circ} \mathrm{C}$ and $0.11 \mathrm{MPa}$ for $15 \mathrm{~min}$. Cultures were maintained at $25 \pm 2{ }^{\circ} \mathrm{C}$ under a $16 \mathrm{~h}$ photoperiod provided by cool white fluorescent light at $50 \mu \mathrm{mol} \mathrm{m}^{-2} \mathrm{~s}^{-1}$. Media and culture conditions were sustained throughout all experiments unless were mentioned other.

\section{Seed surface sterilization}

Seed explants underwent a viability test by soaking in water; any floating seeds were excluded. To achieve faster seed germination under aseptic conditions, seeds were pretreated with $70 \%$ sulfuric acid (v/v) for 30 seconds and washed in sterile-distilled water five times. Seeds were then pre-sterilized with $70 \%(\mathrm{v} / \mathrm{v})$ ethanol for $30 \mathrm{~s}$ and rinsed in sterile distilled water. They were then surface sterilized with $20 \%$ (v/v) Clorox (commercial bleach, 5.25\% hypochlorite) for $15 \mathrm{~min}$ with constant shaking. The seeds were subsequently rinsed thoroughly in sterile-distilled water five times until all traces of Clorox were removed.

\section{In vitro seed germination}

The disinfected seeds were inoculated as two seeds per 100 $\mathrm{mL}$ test tube $(20 \times 4 \mathrm{~cm})$ containing $15 \mathrm{~mL}$ medium. To improve and accelerate germination rate various media were examined. MS medium free of growth regulators were provided in three strengths as zero (water-agar), half and full or full MS, either under $16 \mathrm{~h}$ photoperiod or under darkness condition until germination. Also full MS medium were supplemented with benzyladenine (BA) or kinetin (Kin) at $0.5,1,2,3$ and $5 \mathrm{mg} \mathrm{L}^{-1}$ concentrations. The cultures were observed periodically and germinated seeds were counted. Seeds showed radicle protrusion was considered germinated and days required for germination (DRG) were recorded. Seedling length $(\mathrm{cm})$ and number of nodes were recorded one week after germination. After full germination of cultured seeds, seedlings treated with BA and Kin were subcultured into full MS medium lacking growth regulators.

\section{In vitro propagation}

For micropropagation, 14-days-old seedlings (Fig. 1A) that developed on full MS medium under a 16-h photoperiod were used to prepare stem node explants. All seedlings with 7 to $13 \mathrm{~cm}$ height were transversely cut to segments ( 1 to 1.5 $\mathrm{cm}$ ), each containing one bud (Fig. 1B). Two explants were inoculated per glass bottle $(8 \times 5 \mathrm{~cm}, 200 \mathrm{~mL})$ containing $30 \mathrm{~mL}$ MS medium supplied with BA or Kin at $0,0.5,1,2,3$ or $4 \mathrm{mg} \mathrm{L}^{-1}$ concentrations.

\section{Acclimatization}

Healthy plantlets of $G$. tenax with well developed roots were selected for acclimatization. Selected culture bottles containing plantlets were taken out of the culture room and kept for hardening at room temperature under diffuse sunlight for two days. The plantlets were then removed from medium and washed thoroughly under running tap water to ensure removal of traces of agar.

Plants were cultivated into plastic pots $(5 \times 7 \mathrm{~cm})$
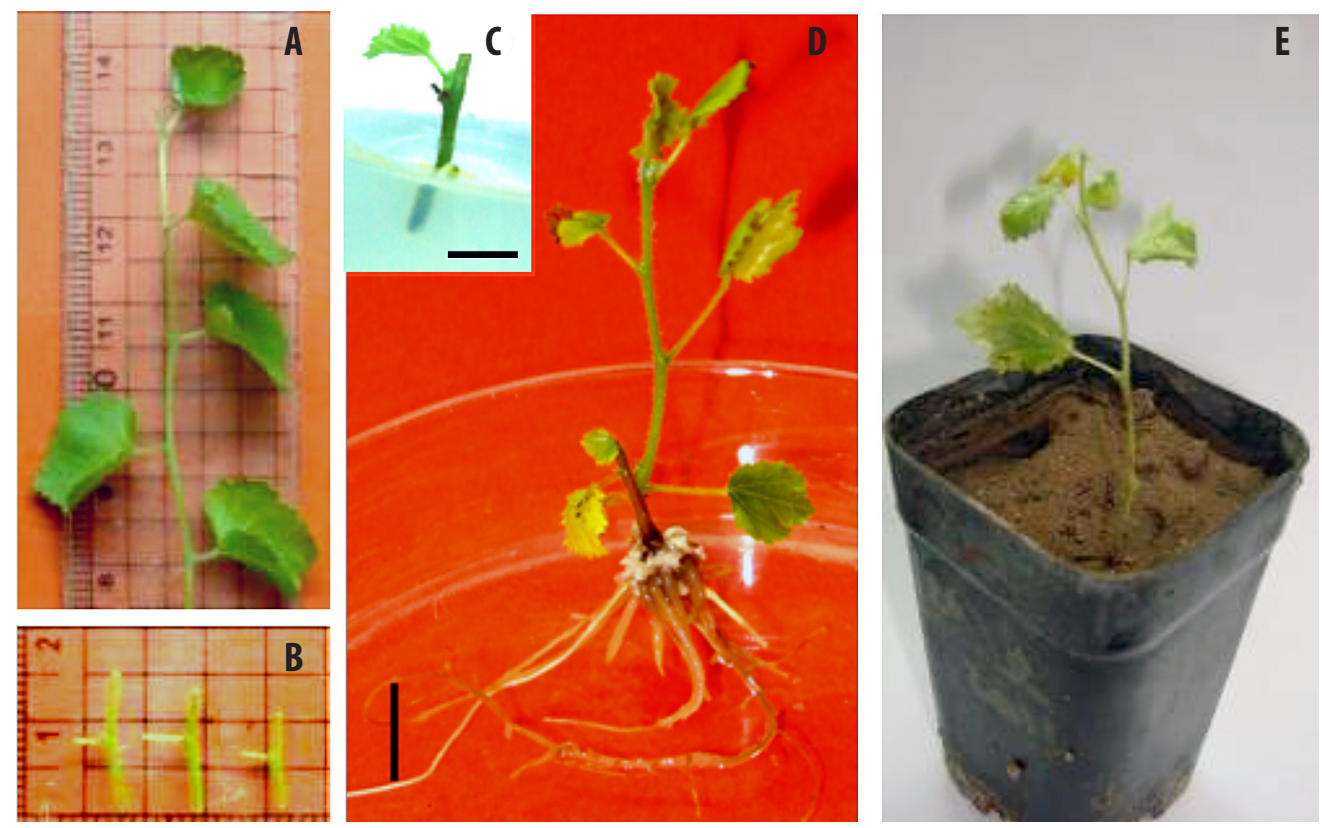

Fig. 1. Micropropagation of G. tenax. A, 14-days-old seedling used for isolation of explants. B, isolated node explants (1.0 to $1.5 \mathrm{~cm}) \mathrm{used}$ for initiation of culture. C, uninodal explant developed one shoot after 6 days of culture (bar $=0.5 \mathrm{~cm})$. D, G. tenax plants after 20 days of culture in MS basal medium ( $\mathrm{bar}=1.0 \mathrm{~cm}$ ). E, acclimatized plants under greenhouse conditions. 
filled with sterilized silt/sand (1:1, v/v) mixture. Each pot was covered with a glass vessel to prevent it from evaporation. Pots were kept under room conditions and irrigated whenever the soil surface dried. After two to three weeks pots were uncovered but remained under the same conditions until growth was observed; e.g., development of a new leaf (for three weeks). The plants were then transferred into polyethylene bags $(15 \times 25 \mathrm{~cm})$ filled with the same mixture of soil and kept in a greenhouse to investigate their ex vitro acclimatization.

\section{Experimental design and statistical analysis}

All treatments were applied in five replicates and repeated twice. A completely randomized design was used in all experiments. The data were subjected to two-way analysis of variance (ANOVA) and Duncan's Multiple Range Test (DMRT) at the 5\% level using Microsoft Excel software.

\section{Results}

\section{Seed germination and seedling growth}

G. tenax seeds were placed in MS medium with different strengths with or without plant growth regulators. Germination was fast and homogenous; the seeds were hydrated by water absorption, and a radicle was observed sprouting out through the seeds coat into the medium. Aerial parts developed showing the typical Malvaceae germination with expanded cotyledonary leaves above the medium. The seed coat was impermeable to water preventing germination, but treatment with sulfuric acid broke the dormancy. Successful $100 \%$ in vitro germination was achieved after two weeks for all treatments. Further development of the seedlings resulted in healthy plantlets after two weeks of culture. The germination prototypes of seeds appeared similar in all growth media under the two light regimes.

Generally, the results of seed germination (Table 1) showed significant variation $(p=0.05)$ between treatments and in all measured parameters except for number of nodes/ shoot under dark condition, which showed nonsignificant differences.

The number of days required for germination (DRG) was significantly affected by light conditions and MS medium strength (Table 1). Under dark condition, G. tenax seeds needed $4.3 \pm 0.4$ days to germinate compared to 5.5 \pm 0.5 days for seeds kept under full light ( $16 \mathrm{~h}$ per day). Seeds required $4.2 \pm 0.3$ days to germinate in water-agar medium. However, this was not significantly different from germination on $1 / 2$ MS ( $4.6 \pm 0.5$ days). Full MS treatment resulted in the longest DRG (6.2 \pm 0.5 days).

Seedling height above media was significantly affected by photoperiod and MS strengths (Table 1). Seeds germinated and grown under dark were shorter under high MS strengths. The longest shoots $(5.2 \pm 0.6 \mathrm{~cm})$ were recorded on distilled-water medium followed by $4.3 \pm 0.2$ $\mathrm{cm}$ on $1 / 2 \mathrm{MS}$ and lastly full MS $(4.2 \pm 0.2 \mathrm{~cm})$. However, seedlings grown under light condition showed opposite results. The maximum length was on full MS $(5.04 \pm 0.2 \mathrm{~cm})$ followed by $1 / 2 \mathrm{MS}(3.96 \pm 0.2 \mathrm{~cm})$ and then $0 \mathrm{MS}(3.84 \pm$ $0.2 \mathrm{~cm}$ ). Seeds under dark germinated more rapidly on the lower MS strength (lower DRG value, Table 1), which later affected the length of grown seedlings. However, under an ideal photoperiod ( $16 \mathrm{~h}$ light), although lower MS strength supported fast germination (lower DRG value, Table 1), full MS with higher nutrition concentration sustained higher growth of seedlings. Darkness had a positive effect on G. tenax seedling length. Seedlings grown under dark had a mean shoot length of $4.7 \pm 0.3 \mathrm{~cm}$ compared to $4.3 \pm 0.2$ $\mathrm{cm}$ in full light (Table 1).

the number of nodes was not significantly influenced by photoperiodic conditions or medium strength (Table 1). Under a 16-h a day photoperiod $4.2 \pm 0.4$ nodes were produced, compared to $3.5 \pm 0.3$ in the dark condition. The maximum number of nodes $(4.4 \pm 0.4)$ was recorded on full MS.

Shoot length and number of nodes per shoot were recorded two weeks after seed sowing. According to DRG values, the treatments differed in time to reach $100 \%$ germination. Consequently, the seedlings generated varied in age. The average DRG for all treatments was five days and

Table 1. Effect of different growth conditions on seeds germination of G. tenax. Values are expressed as mean \pm standard error of at least nine replicates. Means followed by the same superscript letter within a column are not significantly different $(p=0.05)$ using DMRT. DRG, days required for germination. ${ }^{*}$ Shoot length and number of nodes recorded after two weeks of sowing seeds

\begin{tabular}{lcccc}
$\begin{array}{l}\text { Growth conditions } \\
\text { Light condition }\end{array}$ & MS strength & DRG (days) & Shoot length* $(\mathbf{c m})$ & $\begin{array}{c}\text { Number* of nodes } \\
\text { per seedling }\end{array}$ \\
Dark $(24 \mathrm{~h})$ & 0 & $4.2 \pm 0.4 \mathrm{~b}$ & $5.22 \pm 0.6 \mathrm{a}$ & $3.4 \pm 0.2 \mathrm{~b}$ \\
& $1 / 2$ & $4.4 \pm 0.5 \mathrm{~b}$ & $4.68 \pm 0.2 \mathrm{ab}$ & $3.4 \pm 0.2 \mathrm{~b}$ \\
& 1 & $5.0 \pm 0.3 \mathrm{ab}$ & $4.2 \pm 0.2 \mathrm{~b}$ & $3.6 \pm 0.2 \mathrm{~b}$ \\
\hline Light $(16 \mathrm{~h})$ & 0 & $4.5 \pm 0.4$ & $4.7 \pm 0.3$ & $3.5 \pm 0.2$ \\
& $1 / 2$ & $4.8 \pm 0.2 \mathrm{~b}$ & $3.84 \pm 0.2 \mathrm{~b}$ & $3.6 \pm 0.2 \mathrm{~b}$ \\
\hline & 1 & $4.8 \pm 0.6 \mathrm{~b}$ & $3.96 \pm 0.2 \mathrm{~b}$ & $3.8 \pm 0.4 \mathrm{ab}$ \\
& Mean & $6.2 \pm 0.6 \mathrm{a}$ & $5.04 \pm 0.2 \mathrm{a}$ & $4.6 \pm 0.4 \mathrm{a}$ \\
\hline
\end{tabular}


shoot growth was recorded on the $15^{\text {th }}$ day of cultivation; when average age of seedlings was 10 days.

\section{Effect of cytokinins on seed germination of G. tenax} Cytokinins were incorporated in the medium to improve germination and seedling development. On the basis of obtained results of the MS medium strength and experiment, full MS medium was used to culture seeds as it was superior regarding the number of nodes. Seeds were cultured under full dark condition until germination, and then exposed to full light. The medium was supplemented with various concentrations ( 0.5 to $5.0 \mathrm{mg} \mathrm{L}^{-1}$ ) of Kin and BA and compared with MS free-hormone medium for effect on growth: DRG, shoot length, number of shoots, number of nodes and presence of callus (Table 2).

Treatment with $1.0 \mathrm{mg} \mathrm{L} \mathrm{L}^{-1}$ Kin resulted in nonsignificantly decreased $(p=0.05)$ DRG $(5.4 \pm 0.2)$ compared to control $(6.2 \pm 0.6)$.

Shootlength of germinated G. tenax seedlings was slightly higher with application of cytokinins at concentration 0.5 $\mathrm{mg} \mathrm{L}^{-1} \mathrm{Kin}(4.4 \pm 0.1 \mathrm{~cm})$ over the control $(4.2 \pm 0.2 \mathrm{~cm})$. BA resulted in lower shoot elongation (maximum length recorded was $4.0 \pm 0.1 \mathrm{~cm}$ with $0.5 \mathrm{mg} \mathrm{L}^{-1} \mathrm{BA}$ ). However, shoot length did not significantly differ between control and Kin treatments. Increased concentration of BA ( 1 or 2 $\left.\mathrm{mg} \mathrm{L}^{-1}\right)$ greatly suppressed shoot growth $(2.6 \mathrm{~cm})$.

Number of nodes was not higher with application of cytokinins (Table 2) and was similar in Kin $0.5 \mathrm{mg} \mathrm{L}^{-1}$ and control treatments (4.4 nodes per shoot). Number of nodes decreased with increasing cytokinin concentrations. BA treatment resulted in decreased number of nodes, but not significantly compared with the control and Kin treatments.

Multiple shoots were observed from intact nodal regions of developing seedlings. However, the maximum number of multiple shoots $(1.8 \pm 0.8)$ was observed in medium supplemented with $1.0 \mathrm{mg} \mathrm{L}^{-1}$ BA followed by 0.5 $\mathrm{mg} \mathrm{L}^{-1} \mathrm{BA}$ and $1.0 \mathrm{mg} \mathrm{L}^{-1} \mathrm{Kin}$ media $(1.2 \pm 0.2)$. There was no significant effect ( $p=0.05$ ) of cytokinin concentration on mean number of shoots.

Callus formation was observed from the point of root development and surrounding tissues at higher concentrations of Kin and BA (Table 2). The highest BA concentrations ( 3 and $5 \mathrm{mg} \mathrm{L}^{-1}$ ) resulted in excessive callusing.

\section{In vitro propagation of G. tenax}

All nodal explants cultured in MS medium with different concentrations of cytokinins including the control ( 0 to $4.0 \mathrm{mg} \mathrm{L}^{-1}$ ) produced only one shoot/ explant (data not shown). Nevertheless, all explants cultured in BA or Kin media (concentrations 0.5 to $4 \mathrm{mg} \mathrm{L}^{-1}$ ) produced excessive callusing at the base of nodal segments. In contrast, callus did not develop in explants cultured in the control (cytokininfree MS medium). On the other hand, all uninodal explants cultured in control medium produced one shoot from the bud and the root developed at the end of segment into the medium. Thus complete plantlets were generated within one month from all cultured nodal explants.

Self-rooted seedling production might represent a simple technique for in vitro propagation of G. tenax. This could be implemented by generating a large number of plantlets in vitro; each contains number of nodes with axillary buds representing new shoots. Seedlings grown in a culture vessel for 14 days had elongated to approximately 13 $\mathrm{cm}$, bearing an average of 10 nodes (Table 3, Fig. 1A). Each seedling could be subdivided to $1-1.5 \mathrm{~cm}$ nodal segments containing one meristematic bud (Fig. 1B), i.e. generated 10 nodes (Table 3). Each 1-cm nodal segment (which usually included one meristematic bud) was transferred to new growth regulator-free MS medium and cultured up to four weeks. After the first 5 to 6 days of culture, all axillary nodes started to develop a shoot (Fig. 1C). After another 6 to 14 days, the microshoots had elongated and roots emerged from explant ends. As G. tenax easily rooted on PGR-free

Table 2. Effects of Kin and BA supplemented in full MS medium on G. tenax seed germination under $16 \mathrm{~h}$ light. Values are expressed as mean \pm standard error (SE) of at least nine replicates. Means followed by the same superscript letter within a column are not significantly different $(p=0.05)$ using DMRT. DRG: days required for germination. $(-)$ : no callus, $(+)$ : low callus, $(++)$ : medium callus

\begin{tabular}{|c|c|c|c|c|c|c|}
\hline Cytokinin & $\begin{array}{c}\text { Concentration } \\
(\mathrm{mg} \mathrm{L}-1)\end{array}$ & DRG (days) & $\begin{array}{l}\text { Shoot length } \\
\text { (cm) }\end{array}$ & $\begin{array}{c}\text { Number of } \\
\text { shoots }\end{array}$ & $\begin{array}{c}\text { Number of } \\
\text { nodes/shoot }\end{array}$ & Callus index \\
\hline Control & 0.0 & $6.2 \pm 0.6 \mathrm{a}$ & $4.2 \pm 0.2 \mathrm{a}$ & $1.0 \pm 0.0 \mathrm{a}$ & $4.4 \pm 0.4 \mathrm{a}$ & $(-)$ \\
\hline \multirow[t]{5}{*}{ Kin } & 0.5 & $7.8 \pm 0.9 \mathrm{a}$ & $4.4 \pm 0.1 \mathrm{a}$ & $1.0 \pm 0.0 \mathrm{a}$ & $4.4 \pm 0.2 \mathrm{a}$ & $(-)$ \\
\hline & 1.0 & $5.4 \pm 0.2 \mathrm{a}$ & $3.9 \pm 0.2 \mathrm{a}$ & $1.2 \pm 0.2 \mathrm{a}$ & $4.0 \pm 0.3 a$ & $(-)$ \\
\hline & 2.0 & $7.4 \pm 1.2 \mathrm{a}$ & $3.8 \pm 0.3 \mathrm{a}$ & $1.0 \pm 0.0 \mathrm{a}$ & $3.8 \pm 0.4 \mathrm{a}$ & (+) \\
\hline & 3.0 & $8.2 \pm 0.8 \mathrm{a}$ & $2.3 \pm 0.1 b c$ & $1.2 \pm 0.2 \mathrm{a}$ & $2.2 \pm 0.2 b c$ & $(+)$ \\
\hline & 5.0 & $9.2 \pm 1.5 \mathrm{a}$ & $1.7 \pm 0.4 b c$ & $1.0 \pm 0.0 \mathrm{a}$ & $1.8 \pm 0.2 \mathrm{c}$ & $(+)$ \\
\hline \multirow[t]{5}{*}{$\mathrm{BA}$} & 0.5 & $6.6 \pm 0.4 a$ & $4.0 \pm 0.1 \mathrm{a}$ & $1.2 \pm 0.2 \mathrm{a}$ & $4.0 \pm 0.0 \mathrm{a}$ & $(-)$ \\
\hline & 1.0 & $7.0 \pm 0.5 a$ & $2.6 \pm 0.3 b$ & $1.8 \pm 0.8 \mathrm{a}$ & $2.6 \pm 0.2 b c$ & $(-)$ \\
\hline & 2.0 & $8.4 \pm 1.0 \mathrm{a}$ & $2.6 \pm 0.2 b$ & $1.0 \pm 0.0 \mathrm{a}$ & $2.8 \pm 0.2 b$ & $(+)$ \\
\hline & 3.0 & $8.6 \pm 0.7 a$ & $1.8 \pm 0.4 \mathrm{c}$ & $1.0 \pm 0.0 \mathrm{a}$ & $2.0 \pm 0.3 b c$ & $(+)$ \\
\hline & 5.0 & $8.4 \pm 1.1 \mathrm{a}$ & $1.8 \pm 0.4 c$ & $1.0 \pm 0.0 \mathrm{a}$ & $1.8 \pm 0.2 \mathrm{c}$ & $(++)$ \\
\hline
\end{tabular}


Table 3. Average shoot length, number of node, node length and propagation rate of $G$. tenax. ${ }^{*}$ The number of nodes per shoot with length $\geq 1.0 \mathrm{~cm}$. ${ }^{*}$ The proportion of plantlets produced from 10 uninodal explants that arise either from 14 -day-old seedling $\left(1^{\text {st }}\right)$ or from the subculture of plantlets $\left(2^{\text {nd }}\right)$

\begin{tabular}{|c|c|c|c|c|}
\hline \multirow[t]{2}{*}{ Shoot length $(\mathrm{cm})$} & \multirow{2}{*}{$\begin{array}{c}\text { Number of nodes } \\
\text { per shoot }^{*}\end{array}$} & \multirow[t]{2}{*}{ Node length $(\mathrm{cm})$} & \multicolumn{2}{|c|}{ Propagation rate $(\%){ }^{* *}$} \\
\hline & & & $1^{\text {st }}$ & $2^{\text {nd }}$ \\
\hline $13.24 \pm 0.49$ & $10.0 \pm 0.49$ & $1.25 \pm 0.12$ & $99.3 \pm 0.3$ & $99.7 \pm 0.3$ \\
\hline
\end{tabular}

MS medium (Fig. 1D), the 10 nodal segments developed up to 10 plantlets (average 9.9 plants) with a propagation rate of $99.3 \pm 0.3$ (Table 3). Each of these 10 plantlets produced an average of 10 nodes per a plant. Therefore, nodal segments of these 10 plants were resulted in average of 100 nodal explants. The 100 nodal explants produced 100 plants with a propagation rate of $99.7 \pm 0.3$ (Table 3 ) after four weeks of subculture. This system therefore has the potential to develop 100 plants from one seed within three months. Consequently, if every axillary node gives rise to a plant, 1000 plants could be produced after four months.

A survival rate of $95 \%$ was achieved when these plants were transferred to soil under greenhouse conditions (Fig. 1e). The drop in survival in the plastic house could be due to low humidity. However, the plantlets appear healthy and without any phenotypic aberrations.

\section{Discussion}

Seed germination is a mechanism by which morphological and physiological alterations result in activation of an embryo grown from seed. The advantage of using in vitro treatments to induce germination is that it will increase the probability of seed germination, which is essential for further experiments.

In the present study, pretreated seeds cultivated under two light regimes and on three concentrations of MS medium began to germinate after four days. Sohail (2009) reported that $G$. tenax reached final germination after four days, when seeds were previously treated for four weeks. Similar results are obtained for Adansonia digitata (Ishii, Kambou 2007). In vitro germination of $100 \%$ for $G$. tenax seed was achieved after two weeks. Ali and Abd Alla (2003) reported $80 \%$ germination of $G$. tenax seeds cultivated in vitro. Various studies reported ex vitro germination of $G$. tenax with variable percentage of germination in relation to pretreatment of seed before sowing. Saleem et al. (2012) reported the highest germination percentage (93\%) when hot water was used, while Ali and Abd Alla (2003) using the same procedure recorded $85 \%$, and pretreatment of seeds with incubation at $40{ }^{\circ} \mathrm{C}$ for four weeks resulted in $70 \%$ germination (Sohail 2009).

A decrease in days for germination with dark conditions has been reported for other plants. Incubation of seeds in complete darkness was reported to enhance seed germination frequency of Citrus reticulata (Siwach et al. 2012), Withania somnifera (Nathiya et al. 2013) and
Silybum marianum (Khan et al. 2013). Similar effects of MS medium strength on DRG were reported for different species. Martendal et al. (2013) used water-agar medium to achieve maximum germination rate for Byrsonima cydoniifolia. Seed germination of Aconitum heterophyllum was observed in distilled-water medium, but not in MS medium, which was reported to be inhibitory (Solanki, Siwach 2012). Moreover, 0 and $1 / 2$ MS media produced the higher seed germination percentage of Moringa oleifera, compared to full MS medium (Lédo et al. 2008). Likewise, Samuel et al. (2009) showed that reduction of MS salts to half-strength is sufficient to improve the germination percentage of Givotia rottleriformis, compared to quarterand full-strength. Germination of seeds in media lacking nutritional salts and sucrose might occur because embryos were autotrophic and eliminate the supplemental energy source (Martendal et al. 2013). On the other hand, Solanki and Siwach (2012) considered that delay in germination of seeds on full MS basal medium occurred because the salt concentrations exceeded seed germination needs. Dissimilarity in responses of seed to different salts formulations was also reported by Solanki and Siwach (2012) and Ghorpade et al. (2010). A higher germination rate is an important factor for establishing plant tissue culture and is particularly useful when there is a need to submit a uniform set of seedlings to a treatment.

The results of this study showed that, the effect of MS nutrition interacts with light conditions. Under dark condition, length decreased with increasing medium concentration, while length increased with decreasing medium concentration under light. A similar negative effect of medium strength on seedling growth was reported for other species. The best growth in shoot length of Byrsonima cydoniifolia cultivated on different media was obtained on water-agar medium (Solanki, Siwach 2012). Seed culture of Givotia rottleriformis (Rambabu et al.2006) and Pterocarpus marsupium (Chathurani et al. 2009; Mishra et al. 2013) showed decrease in shoot length of seedlings germinated on full MS compared to half strength. Chathurani et al. (2009) suggest that the levels of salts in MS medium may have been unnecessarily high, resulting in slowing growth or even toxic effect.

The number of nodes was more important than shoot length for direct propagation. In this study, a photoperiod of $16 \mathrm{~h}$ and full MS are the optimum conditions for production of nodes. Similar findings were observed on Dianthus serotinus; the number of nodes per shoot was 
reduced when seedlings were grown on half strength MS medium (Marković et al. 2013). Variation in number of nodes according to media types is also reported (Chathurani et al. 2009).

The overall results showed that $G$. tenax seeds responded well to in vitro conditions because germination process was successfully completed with radicle protruded through seed coat and growth of cotyledons. Water medium in dark accelerated germination rate and resulted in higher shoot length in comparison to MS medium in light. However, plantlets on full MS medium under 16-h photoperiod produced the maximum number of nodes. Darkness stimulated hypocotyl elongation but did not alter the number of nodes. It can be assumed that water medium in dark would be useful for production of seedlings in vitro, reducing production cost. However, in order to produce maximum number of nodes, the use of full MS under light is recommended. Based on that, seeds can be considered as a good starting material for in vitro establishment of $G$. tenax.

Cultivation of seeds on MS medium supplemented with Kin and BA did not improve germination rate or seedling growth. This result was in contrary with that reported for different tree species. Germination percentage of Adansonia digitata seeds increased from $75 \%$ in hormonefree medium to $91 \%$ when the medium supplemented with BAP (Ishii, Kambou 2007). Germination frequency of Prunus armeniaca seeds reached $100 \%$ when cultivated on MS medium supplemented with $1.0 \mathrm{mg} \mathrm{L}^{-1} \mathrm{BA}$ (Nathiya et al. 2013). Samuel et al. (2009) suggested that supplementing the medium with Kin is essential to achieve efficient plant conversion from embryo of Givotia rottleriformis. Seeds of Prunus armeniaca produced the highest mean shoot length in MS medium supplemented with BA (Nathiya et al.2013). The same concentration of BA produced the longest shoots formed on embryo of Boscia senegalensis compared to other treatments (Daffalla et al. 2011).

Cultivation of nodal explants for micropropagation on cytokinin-containing media resulted only in one shoot. Similar results were reported in other experiments with G. tenax (Ali, Abd Alla 2003) and Grewia asiatica (Biswas et al. 2005). Excessive callusing hindered shoot induction in this study, which was also reported in previous study of G. tenax (Ali, Abd Alla 2003) and Grewia asiatica (Biswas et al. 2005). Presumably in tissues that are able to grow without cytokinin being added to the medium, the cells can produce sufficient natural cytokinin for cell division to proceed (Van Stedan et al. 2008). However, cultivated nodal explants produced complete plantlets. Self-rooting seedling production might represent a simple technique for in vitro propagation of G. tenax.

This study confirmed that seed germination of G. tenax requires that seed-coat imposed dormancy is broken by scarification. A rapid germination rate of seeds was achieved using water-agar medium under dark condition. Full MS under ideal light was optimal for production of nodes. Medium for direct shoot induction using cytokinins needs to be modified to minimize callus intervention. Production of a large number of plantlets, self-rooting shoots was obtained by cultivating nodal explants on MS medium free of PGRs. The protocol for producing in vitro multiple plants over a short period of time was successful and provided a continuous supply of healthy propagules. One of the advantages of this regime is that it uses renewable shoot material and it has the potential to generate approximately 100 plants from one seed explant over a 10 week cycle and without using PGRs. This is highly desirable for large scale propagation of this very important nutraceutical plant.

\section{References}

Ali Y.H., Abd Alla M.A. 2003. Vegetative propagation of Grewia tenax (Forsk.) Fiori by stem cuttings and micropropagation. Sudan J. Basic Sci. Sect. B Biol. Sci. Vol. 3.

Anonymous. 2000. First national report on the implementation of the convention on biological diversity. The Higher Council for Environment and Natural Resources (HCENR), Government of the Republic of the Sudan, Ministry of Environment and Tourism, Khartoum, Sudan.

Biswas B., Joshee N., Yadav A., Yadav A.K. 2005. In vitro propagation and somatic embryogenesis in Phalsa. Hort Sci. 40: 1104.

Daffalla M.H., Abdellatef E., Elhadi E.A., Khalafalla M.M. 2011. Effect of growth regulators on in vitro morphogenic response of Boscia senegalensis (Pers.) Lam. Poir. using mature zygotic embryos explants. Biotechnol. Res. Int. 2011: 710758.

El Ghazali G.E.B., El Tohami M.S., El Egami A.A.B., Abdalla W.S., Mohammed M.G. 1997. Medicinal plants of the Sudan, part IV: Northern Kordofan. Omdurman Islamic University Printing and Publishing House, Khartoum, Sudan.

El Tahir B.A., Gebauer J. 2004. Non-timber forest products: Opportunities and constraints for poverty reduction in the Nuba Mountains, South Kordofan, Sudan. Conference on International Agricultural Research for Development, Deutscher Tropentag, October 5-7, Berlin, Germany.

El-Siddig K., Gebauer J., Inanaga S., Ludders P. 2005. Auxin effects on rooting of stem cuttings of Grewia tenax: A potential alleviator of iron-deficiency anemia in the Sudan. The Global Food and Product Chain - Dynamics, Innovations, Conflicts, Strategies, October 11-13, 2005. Deutscher, Tropentag, Hohenheim, Germany.

Gebauer J., El-Siddig K., El Tahir B.A., Salih A.A., Ebert G., Hammer K. 2007. Exploiting the potential of indigenous fruit trees: Grewia tenax (Forssk.) Fiori in Sudan. Genet. Resour. Crop Evol. 54: 1701-1708.

Ghorpade R., Chopra P.A., Nikam T.D. 2010. In vitro zygotic embryo germination and propagation of an endangered Boswellia serrata Roxb., a source of boswellic acid. Physiol. Mol. Biol. Plants 16: 159-165.

Chathurani G.D.G., Subasinghe S., Jayatilleke M.P. 2006. In-vitro establishment, germination and growth performance of Red Sandalwood (Pterocarpus santalinus L.). Trop. Agric. Res. Extension 9: 117-130.

Ishii K., Kambou S. 2007. In vitro culture of an African multipurpose tree species: Adansonia digitata L. Propag. Ornam. Plants 7: 62-67. 
Khan M.A., Abbasi B.H., Ahmed N., Ali H. 2013. Effects of light regimes on in vitro seed germination and silymarin content in Silybum marianum. Ind. Crop. Prod. 46: 105-110.

Lédo A.S., Rangel M.S.A., Freire K.C.S., Machado C.A.L., Oliveira F.M. 2008. Sexual propagation in vitro of Moringa (Moringa oleifera Lam). Bol. Pesqui. Desenvolv. 39: 5-18.

Marković M., Grbić M., Djukić M. 2013. Micropropagation of the endangered and decorative specie Dianthus serotinus Waldst. et Kit. Not. Bot. Horti Agrobot. 41: 370-377.

Martendal C.O., Bernardino M.M., Pereira F.D., Silva F.G., Menezes C.C.E., Hara A.C.B.A.M. 2013. In vitro cultivation of zygotic embryos from Murici (Byrsonima cydoniifolia A. Juss.): establishment, disinfection, and germination. Acta Sci. Agron. 35: 221-229.

Mishra Y., Rawat R., Nema B., Shiri F. 2013. Effect of seed orientation and medium strength on in vitro germination of Pterocarpus marsupium Roxb. Not. Sci. Biol. 5: 476-479.

Murashige T., Skoog F. 1962. A revised medium for rapid growth and bioassays with tobacco tissue cultures. Physiol. Plant. 15: 473-497.

Nathiya S., Pradeepa D., Devasena T., Senthil K. 2013. Studies on the effect of sucrose, light and hormones on micropropagation and in vitro flowering of Withania somnifera var. Jawahar-20. J. Anim. Plant Sci. 23: 1391-1397.

Rambabu M., Upender M., Ujjwala D., Ugandhar T., Praveen M., Swamy N.R. 2006. In vitro zygotic embryo culture of an endangered forest tree Givotia rottleriformis and factors affecting its germination and seedling growth. In Vitro Cell. Dev. Biol. Plant 42: 418-421.
Saied A.S., Sohail M., Gebauer J., Buerkert A. 2010. Response of Grewia tenax (Forssk.) Fiori to NaCl-induced salinity. Eur. J. Hort. Sci. 75: 42-50.

Saleem N.A., Mohamed K.A.A., El Nour M. 2012. Different growth characteristics of Grewia mollis, Grewia tenax and Grewia villosa under nursery and field conditions. J. Life Sci. 6: 1016-1024.

Samuel, K., Debashish, D., Madhumita, B., Padmaja G., Prasad S.R., Bhaskara V., Murthy R., Rao P.S. 2009. In vitro germination and micropropagation of Givotia rottleriformis Griff. In Vitro Cell. Dev. Biol. Plant 45: 466-473.

Sharma N.,Patni V.2012. Grewia tenax (Frosk.) Fiori. - A traditional medicinal plant with enormous economic prospectives. Asian J. Pharm. Clin. Res. 5: 28-32.

Siwach P., Chanana S., Gill A.R., Dhanda P., Rani J., Sharma K., Rani H., Kumari D. 2012. Effects of adenine sulphate, glutamine and casein hydrolysate on in vitro shoot multiplication and rooting of Kinnow mandarin (Citrus reticulata Blanco). Afr J. Biotechnol. 11: 15852-15862.

Sohail M.2009. Ecophysiology of seed dormancy and salt tolerance of Grewia tenax (Forssk.) Fiori and Ziziphus spina-christi (L.) Willd. PhD. dissertation, University of Kassel, Germany.

Solanki, P. and Siwach, P. 2012. Optimization of conditions for in vitro seed germination and shoot multiplication of Aconitum heterophyllum Wall. Int. J. Med. Arom. Plants. 2:481-487.

Van Stedan J., Zazimalova E., George E.F. 2008. Cytokinins, their analogues and antagonist. In: George E.F., Hall M., Delkleck G.J. (eds) Plant Propagation by Tissue culture. Plant growth regulators II. Springer, Netherlands, 1: 205-226. 